
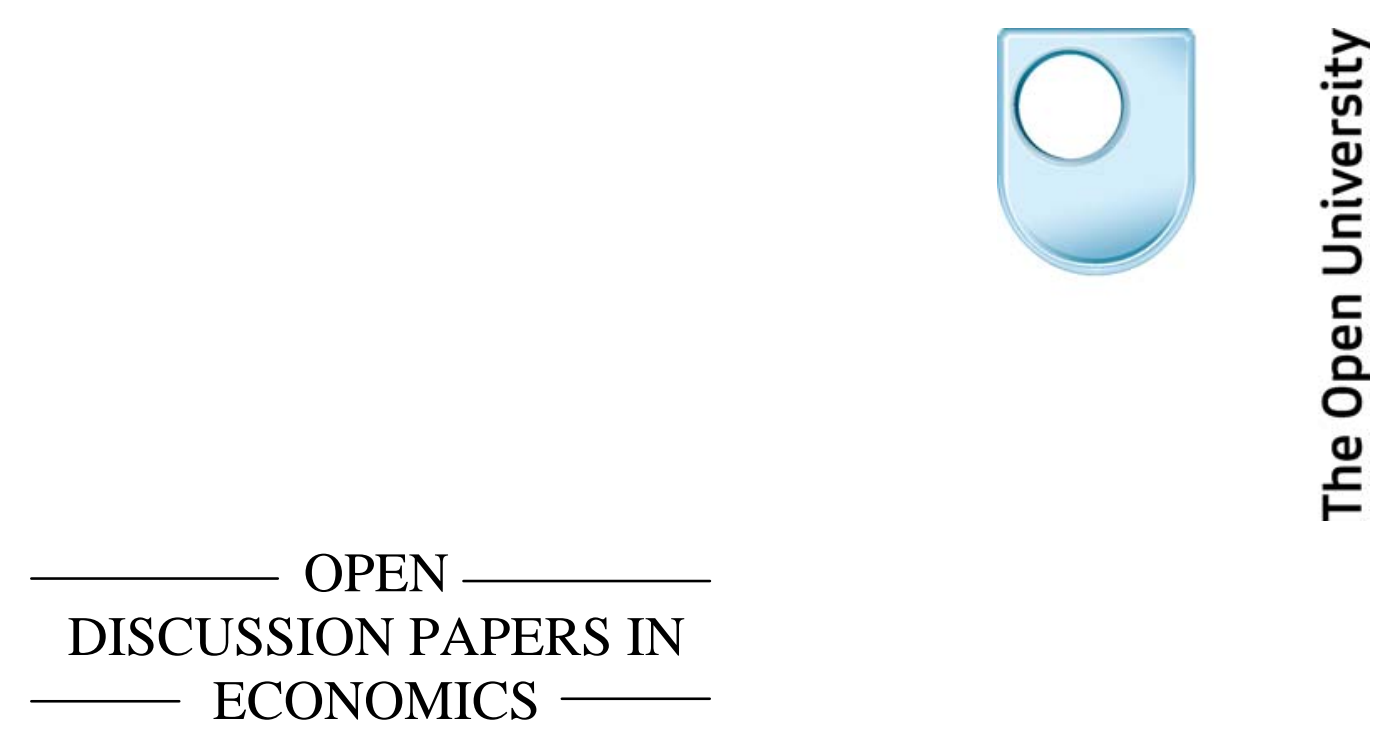

The Measurement of Capabilities:

\author{
Paul Anand \\ The Open University
}

Cristina Santos

The Open University and University College London

\author{
Ron Smith \\ Birkbeck College, London
}

November 2007

NUMBER 67 
Copies may be obtained from:

Economics Department

Faculty of Social Sciences

The Open University

Walton Hall Milton Keynes MK7 6AA

Telephone: 01908654437

Email:_economics@open.ac.uk

Fax: $\quad 01908654488$

This series is registered under

ISSN 1753-2590 (Print)

ISSN 1753-2604 (Online) 


\section{Economics Research at The Open University}

Throughout the 1990s, The Open University has been developing its research capacity in economics. Economists at the OU comprise a lively and expanding group with a wide set of interests ranging from development policy to decision theory, from Marxist theories of profit to libertarian foundations of environmental policy and from econometric analysis of large data sets through institutional economics to the use of case-studies in policy formation. Nearly a 1000 students from around the world register each year to study economics courses and their needs, together with the multi-disciplinary nature of social science at the university, shape out research. Through a variety of personal and group research projects, our work makes a strong contribution to areas like business, public policy and even philosophy where sharply focused analysis can inform decision-making as well as contribute to scientific progress.

In 1999, approximately $£ 250,000$ million worth of externally funded grants (3 from the ESRC) were held by discipline members, some of whom also act as consultants to national and international bodies. Approximately half a dozen students are currently reading for doctorates with members of the discipline and we are always interested in proposals from colleagues or potential students who would like to do research with us.

Some of the journals in which discipline members have published include: Annals of Operations Research, Economic Journal, Economica, Economics and Philosophy, Feminist Economics, Feminist Review, International Journal of the Economics of Business, International Journal of Industrial Organisation, Journal of Economic Issues, Journal of Economic Psychology, Journal of Evolutionary Economics, Journal of the History of Ideas, Journal of Social Policy, Local Government Studies, The Locke Newsletter, Open Learning, Oxford Economic Papers, Public Policy and Administration, Radical Statistics, Review of Economic Dynamics, Revue d' Économie Politique, Risk Decision and Policy, Structural Change and Economic Dynamics, Technovation and Theory and Decision.

The papers contain results of economic research which are the sole responsibility of the authors. Opinions expressed in these papers are hence those of the authors and do not necessarily reflect views of the University. 
The Measurement of Capabilities:

Paul Anand, The Open University

Cristina Santos, The Open University and University College London

Ron Smith, Birkbeck College, London 


\title{
The Measurement of Capabilities
}

\begin{abstract}
It has often been claimed that it is impossible to measure human capabilities but within the methodological conventions of household survey design, we show that some non-financial capability indicators do already exist and we demonstrate how similar indicators, covering a wide range of life domains, can be constructed. This chapter draws on a continuing research project which contributes to the operationalisation of the capabilities approach by devising over 60 capability indicators which can be used to extend coverage of indices such as HDI, illustrating different ways in which such indicators may be analysed, and discussing some of the associated methodological issues that have emerged in the process. Based on usable observations from a national UK sample of 1000 adults, we use latent class analysis to identify an impoverished group of respondents with low capabilities across the board, build models of experienced violence and subjective wellbeing as a function of experienced and anticipated violence, and explore the relationship between capability indicators and subjective wellbeing. Substantive findings include: the identification of a group with low all round capabilities associated with low health and low income; evidence that fear of future violence can be a more significant determinant of subjective wellbeing than past experience of violence; and evidence which supports the view that a large diverse set of non-financial dimensions of capability have a detectable impact on subjective wellbeing. We conclude by discussing some of the econometric issues that have emerged in the course of this work.
\end{abstract}

JEL Codes: D60, C80

Words for Index

capabilities, measurement, performance indicators, human development, welfare, economic statistics, freedom, happiness, subjective wellbeing, personality, gender differences, violence, causality, poverty, health, latent class analysis 


\section{The Measurement of Capabilities}

\section{Introduction}

From the variety of conceptions of what constitutes a good life that policy might promote, we focus on two. One emphasises the freedoms and rights that people have, what Sen calls their capabilities. The other emphasises individual well-being derived from what individuals do. The capabilities approach to welfare has focused on issues of freedom but both freedom and wellbeing appear in his formal account of the approach, Sen (1985) and Sen and Nussbaum (1993), in which he suggests that a person's happiness depends on what the person does, whilst assessment of a person's advantage should depend, in addition, on the other things that person could do. ${ }^{1}$

These two approaches to quality of life potentially conflict. According to the first view, the right to vote for example is a good thing; it makes people capable of doing something, probably something they have reason to value, and it may remain a good thing not only if people do not vote but if people would prefer not have the right to vote and would feel better if somebody else made the decisions for them. According to the second view, what counts is just wellbeing and if that is greater under a regime in which everyone does not have the right to vote and can avoid the need to make decisions, then policy should promote not having the right to vote.

In deciding between these two views, there are many normative questions, but there is an informational issue also. It is far easier to find out whether a particular group of people do or do not have the right to vote than it is to find out whether they would prefer having the vote or not. In principle, these are quite distinct and non-comparable philosophical issues. ${ }^{2}$

In practice, for policy purposes, they might not be so different. If capabilities and wellbeing were, in fact, highly correlated, contrary to the voting example, then extending people's capabilities would (on average) increase their well-being. If an expansion of capabilities increased, or at least did not reduce, wellbeing, it could be argued that policy should be aimed

\footnotetext{
${ }^{1}$ Further theoretical development can be found in Gaertner and Xu (2005), van Hees (2004), Nehring and Puppe (2005) and Pattanaik and Xu (1998) and a number of key philosophical issues are examined by Carter $(1999,2003)$. The origins of the capabilities approach in problems to do with conventional social choice and welfare economics are particularly evident in Sen (1979).

${ }^{2}$ Initially, researchers were pessimistic about the prospects of broadening capability indicators beyond those available through the Human Development Index (see, for example, Brandolini and D'Alessio (1999)). However, there are now a number of attempts to do quantitative empirical work in ways that engage with the approach - see for instance Burchardt and Le Grand (2002), Brower et al (2004), Chiappero-Martinetti (2000), Clark (2003), Klasen (2000), Kuklys (2005), Laderchi (2001), Schokkaert and Ootegem (1990).
} 
at capabilities development even if wellbeing maximisation was the ultimate objective. These are variants of the information argument above, that it is easier to determine capabilities than wellbeing; the freedom argument is that policy should extend the range of things that people can do rather than prescribe what they should do since peoples tastes differ. Indeed one could argue that freedom and autonomy have been central to economic thinking and that the emphasis on optimal goods bundles as the source of happiness is inadequate for some policy purposes.

In any case, whether capabilities and wellbeing are correlated is an interesting and important empirical question and answering it faces a number of issues. How do we measure capabilities? How do we measure wellbeing? Since we are considering average relations over a sample, what statistical methods can be used to estimate the association between capabilities and wellbeing over the sample and infer any causal relationship between them? Having measured capabilities and well-being and estimated the relationship between them, can we begin to derive policy implications from our results?

In this paper, we provide an overview of a research project that tries to address some of these issues. In particular, we focus on the questions of whether and how capabilities can be measured and then go on to consider some of the ways in which capability data can be analysed. We then focus on three topics that are of particular interest from a capabilities perspective: health and poverty, forms of violence and the correlates of life satisfaction. In each case, there is good theoretical or a priori reason to suppose that the capabilities approach can contribute to our understanding. In the first case, we use latent class analysis to explore capabilities from a multi-dimensional angle and determine whether there exists, for our national sample, a group of people who are impoverished with respect to their capabilities across the board. Next, we focus on the existence of different types of violence and how these impact on wellbeing and on capabilities. We identify a group who are more vulnerable to each type of violence and we identify the causal impact of violence on wellbeing. Finally, we consider the role of capabilities on life satisfaction (happiness) which many conventional economists have recently shown interest in and ask whether there is evidence of any detectable relationship between capabilities and life satisfaction across a range of life domains. Although the project was initially motivated by a desire to determine whether capability indicators could be constructed, a number of related methodological issues have emerged and these will be commented in the results section. One particularly interesting issue that arises as we move from theory to empirical work concerns causality. For instance, it may be that some unobserved variable, e.g. personality, influences both an individual's perceived capabilities and their expressed wellbeing, so the association between capabilities and 
wellbeing is non-causal. However, appropriate data design and data-merging allows us to make some headway in addressing questions of causality as our work on the relationship between expectations of violence and life satisfaction indicates.

\section{Capabilities and Wellbeing: Motivation and Operationalisation}

Sen's (1985) formalisation of the capabilities approach defines two key relations. To begin, Sen suggests that happiness or utility, $u_{i}$, of the $i^{\text {th }}$ individual, is a function of the things a person is or does:

$$
u_{\mathrm{i}}=f_{\mathrm{i}}\left(\mathbf{f}_{\mathrm{i}}\right)
$$

where $\mathbf{f}$ is a vector of $\mathbf{j}$ dimensional functionings (doings or beings) and $f_{\mathrm{i}}$ is a utility function that relates functionings to happiness and varies between individuals recognising that preferences are not homogenous. Sen then goes on to argue that what people can choose is also important for welfare and policy purposes and proposes that the set of functioning vectors a person could choose given their endowments broadly defined, Q, be taken as a measure of a person's advantage in welfare evaluations. Many researchers have argued that the capabilities approach is difficult to implement in practice because the set $\mathrm{Q}$ cannot be enumerated. Our project recognises that many, if not most of the welfare statistics available, are more accurately conceived of as indicators and that the proper economic statistics question is not whether capabilities can be enumerated, but rather whether it is possible to construct statistics that indicate the size of $\mathrm{Q}$ in a manner consistent with theory and the accepted methodologies of survey design and social statistics. For what follows, we assume that the empirical measurement challenge is one of developing appropriate indicators.

\section{Measurement of Capabilities}

As a first pass at measuring aspects of $\mathrm{Q}$ in practice, a primary dataset based set of questions that distinguished between achievements and scope in people's lives was devised, Anand and van Hees (2006). Using the distinction between scope and achievement is only one way of measuring capabilities (as distinct from functionings) and it led us to reconsider whether there might not, in fact, be some secondary data that relates more directly to the freedom aspects of capabilities. Using data and questions that exist in secondary datasets, like the BHPS and GSOEP, which are routinely used by economists and social scientists, Anand (2005) and Anand Hunter and Smith (2005), argued that social and household surveys do already contain data that measure capabilities. At least five kinds of indicators can be identified: 
Type 1: Externally Oriented Questions about Opportunity

Type 2: Explicit Questions about Personal Ability Aspects of Capability

Type 3: Explicit Constraint Questions

Type 4: Functioning Probes combined with Questions about Reasons

Type 5: Functioning Probes combined with a Universality Assumption

Questions about access to facilities, like the use of a car or van when needed, and questions about the existence of factors preventing people from moving house illustrate questions capable of generating type 1 and 2 indicators. In some cases, it is possible to use questions about functionings, when combined with reasons, to determine whether a particular behaviour or state reflects a person's preference or inability to make certain choices. And in a smaller number of situations, functioning questions, for example about the experience of violent assault, can be assumed to indicate evidence of a reduced capability set.

Whilst such indicators are used frequently in social science and official statistics, economists often question the validity of such data because of its apparent subjectivity. In an ideal world, data based on objective observation would be preferable but in reality many data sources, including many of the secondary data sources regularly used by economists (eg income data from household surveys), are based on self-report. This is almost inevitable if one wants to analyse individual level data covering a wide range of life domains (given the way social and administrative statistics are collected) and we suggest that two related questions are particularly important when doing so. First, are there any particular incentives for data to be biased or noisy and second if such problems exist, what is their likely impact on analysis. In many cases, once a person has agreed to take part in a survey, the incentives to misrepresent may not be strong, though of course accurate recall is difficult with the result that data on relations between variables may underestimate true, underlying relations. Furthermore, in regression analyses, there are endogeneity risks associated with using subjective variables from the same respondent on both sides of an equation and the project has considered how this might be tested for and suitable instruments devised (not discussed in this chapter but see Anand, Hunter and Smith (2005)). Finally, and beyond this, many capabilities are inherently subjective. The question "how safe do you feel?" does not have an objective answer since it depends on probabilities of harm a person's risk-aversion and a person's behaviour: for example whether they go out at night, will also reflect a variety of other factors that influence the costs and benefits of action.

Measurement of Happiness (Wellbeing) 
To measure happiness, we note that a growing number of economists have moved beyond the use of income as a utility indicator and examine data on self-reported happiness as a more accurate measure of what Kahneman (1997) et al. call 'experienced utility' (see, for instance, Frey and Stutzer A (2000), Kahneman et al (2004), Layard (2005), Oswald (1997), Winkelmann and Winkelmann (1998)). ${ }^{3}$ This move is consistent both with utilitarian theory (if not the methods of revealed preference) and the capabilities' approach emphasis on nonfinancial aspects of quality of life though there are normative issues which suggest asymmetries in use. Many utilitarians claim that we should prioritise only those sources of disadvantage to which individuals do not adapt ${ }^{4}$, whilst proponents of the capabilities viewpoint out that many women have adapted to inequities in labour markets but that this is not a reason to fail to promote equality of opportunity. However, there are some adaptations that many would recognise as healthy and desirable from a welfare perspective and yet there is no account of what role adaptation should play. We take the view, therefore, that the role of adaptive preferences in theories of equity and justice has become confounded with the somewhat different issue concerning the methodological issues surrounding subjective data, particularly those to do with noise and bias in estimation, and endogeneity within regression models. In this project, where a summary measure of wellbeing is a useful, we therefore argue that happiness can play a useful role, particularly if we account properly for the implications that it may have for estimation and model building.

\section{Data}

The data used in our analysis comprise a quota sample of approximately 1000 individuals selected at random from a panel constructed to be roughly representative of the adult population in mainland Britain. The survey process was implemented by an opinion polling and market research company, YOUGOV, in the early part of 2005. In keeping with emerging practice driven largely by data-protection constraints and the spread of internet access and use, the panel comprises people who have previously agreed to be contacted by the company for market research purposes and so cannot be treated as random. That said we were able to use some replicated substantive and socio-demographic questions from the BHPS and found that statistically our results were identical, or very close, to those found there so there is some

\footnotetext{
${ }^{3}$ In his Econometrica survey, Manksi (2004) concludes that subjective measures fare better in terms of statistical accuracy than might have been supposed. (Recognising this accuracy point does not commit one to accepting that evidence of affective adaptation should be used to discount policies aimed at eradicating social and economic problems to which people adapt.)

${ }^{4}$ Where we model life satisfaction, the justification is that adaptation to changes in circumstances is likely to be neither perfect nor instantaneous. Recent work by Di Tella et al (2007) substantiates this and helps to quantify the rate of adaptation where it takes place though they find that people tend to adapt more readily to income changes than to changes in status.
} 
reason to believe that our results have some representative value in addition to demonstrating the methods developed.

\section{Results}

a) Capabilities, Poverty and Health

In the first of our three results sections, we use multivariate, non-dependency techniques to understand capability indicators on their own. Such techniques have been used by statisticians and social scientists in a wide range of applications (see Everitt and Dunn (2001)). In this case, we use latent class analysis to categorise respondents on the basis of all their capability indicators. This allows us to assess whether there is a group who are capability poor across the board and to examine the covariates of category membership. Results of this exercise appear in tables 1a, $1 \mathrm{~b}$ and $1 \mathrm{cb}$ below. To determine the appropriate number of latent classes we compute models without a covariate matrix, $\mathbf{x}$, and select the model that minimises the value of the Bayesian Information Criterion. This statistic is generally used as it provides a measure of fit, adjusted for the number of parameters involved. According to this criterion, a model in which there are six latent classes provides the optimal balance between fit and parsimony.

When a variety of 6 class models as a function of health status are estimated, we observe that variations in health status are always statistically significant predictors of class membership. (Table 1b summarises findings for a series of such models.) The same is true of household income though the test statistics tend to be even more significant for health. The status of health as a class predictor appears robust to the introduction of controls, though in the final model summarised, the controls for age and its square are not significant, whereas three out of the four regional controls are. This is in marked contrast to equations where capabilities are covariates of life satisfaction (e.g. Anand et al (2005)) and in which age is always significant but regional controls rarely are. It is noticeable that all five dimensions of personality are statistically significant, a finding in keeping with work reported by Halliday [ $\left.{ }^{\mathrm{i}}\right]$ recently in his quality of life work based on models of life satisfaction. Clearly, personality is a source of heterogeneity (see also Clark et al (2005)) but we are unable to further identify the reasons for this variation. It may be, for example, that people with different personality traits have different opportunities open to them either as a result of the way in which they themselves cope with adversity or because of the supportive behaviour their traits induce in others. Alternatively, it could be that different personalities are associated with different levels of adaptive coping and/or reporting behaviours. 
By examining the average capability scores across for each group across all the indicators we can begin to assess whether there is a particularly poor group within our sample. In fact, class 6 , which accounts for just over $8 \%$ of our sample, does indeed appear to depict such a group. Generally the average capability indicator scores of class 6 are either the most extreme of all groups, or close to being so, with only a small number of modest exceptions. From Table 1c, it is possible to compare some of the characteristics (covariate averages) of class 6 with those of other groups. Just over half this group (52.99\%) have limited health and this is a notably higher proportion than for any other group. This is also the youngest group on average perhaps the opposite of what one might expect until we recall that the question about health status asks respondents to condition on activities for people of a similar age. Class 6 is also lowest on the income category indicator and just over $60 \%$ of class 6 members are female. The group has low scores on four of the personality dimensions with the exception of openness which is relatively high on class 5 that, in turn, is only marginally better off than class 6 . However, the highest average score for openness is found in class 3 which is possibly the most affluent group so we cannot infer a simple relation between openness and deprivation. It is also noticeable that there is a geographical bias towards England (especially the south) and this may reflect higher levels of health and social care in Wales and Scotland though there could be a comparison effect at play. Reference class effects have been found to be empirically significant in the literature on income and life satisfaction (see Clark Frijters and Shields [ ${ }^{\mathrm{ii}}$ ] for example) and it could also be that capability deprivation is felt more keenly in the south of England because ambient capability levels are higher on average.

\section{b) Violence, Vulnerability and Life Satisfaction}

In this second section, we draw on an analysis of capability indicators concerning data relating to the experience and subjective risk of violence (Anand and Santos 2007), an issue that Nussbaum (2000) and Sen (2006) have both done much to highlight. The section shows how our capabilities measurements can generate data which can be used to understand very specific topics, and that future risks, which might constrain what a person can do, can be measured and used in analysis. In what follows then, we concentrate on the different experiences that men and women have of different forms of violence, their covariates and their consequences for quality of life. With this focus we are able to identify a causal impact, through the pathway of expectations, between violence and wellbeing.

Within our set of capabilities indicators, we have a total of eight variables, two measures of fear of walking around one's locality, during the day and at night, and a further six variables that measure both experienced and perceived risk of violence in three categories (sexual assault, domestic violence and the residual category). Our extensions to the original formal 
capabilities framework (in Sen (1985)) derives from the recognition that there may be significant probabilistic aspects of capabilities ${ }^{5}$ between people and as can be seen from Tables $2 \mathrm{a}$ and $2 \mathrm{~b}$, there are significant differences both in the proportions of female and male respondents reporting experience of violence in each category as well as in their perceived risks of sexual and domestic violence. To understand the causes, or at least covariates, of experienced violence we present six probit models (see Table 2c) in which we use covariate data on age, marital status, income both individual and household, ethnicity, family size, education, personality, local crime rates and a set of regional dummies.

Being separated is associated with other forms of assault reported by women and domestic violence reported by men and it is possible that the primary causal link is different between the sexes - separated women are most at risk of other forms of assault whilst experience of domestic violence by men is more likely to be related to a subsequent separation. However, perhaps the most significant results are those on income for women. There is some evidence that domestic violence significantly decreases as household income increases but controlling for this, there is some evidence (not significant) that women with higher personal incomes are more at risk of experiencing domestic violence. We should be particularly cautious about this as the result is not significant but it suggests that there may be a resentment effect which causes women with higher incomes than their partners to be at a higher risk. If that were indeed the case, it would suggest that social policy programmes designed to reduce domestic violence could not automatically assume that increasing women's income and human capital would reduce their risk, a policy that might otherwise help women exit violent relations as Agarwal (2006) has proposed. It is also worth noting that of all the personality traits being agreeable is a significant risk for women especially and this in turn may mean that behavioural therapies, along side economic issues, could play a significant role in violence reduction programs.

Ultimately, we were interested in assessing the impact of experienced and the threat of violence on wellbeing. Table $2 \mathrm{~d}$ shows the results. We find that the measures of experience, with the exception of domestic violence for women, are not significant.

However, it is particularly note-worthy that this effect disappears when risks are introduced. In the case of all three forms of violence, the coefficients are significant though the pattern is not the same for men, a fact that might suggest either that the quality of life impacts of fear of violence are more severe for women or that the average severities of violence experiences are

\footnotetext{
${ }^{5}$ The ability to walk about safely at night, much discussed in the literature, provides a good example.
} 
particularly different for men and women. There is not much evidence that income has an impact on life satisfaction here though there is some evidence that household income does have an impact for men. Being without a partner, non-white British and introverted all have a negative effect that is statistically significant. Crime rates are also significant but in the wrong direction suggesting, perhaps, that crime rates are correlated with the existence of other local resources that make an area more attractive to live in - shops, pubs, local services encourage people to reside in an area but they also provide opportunities for criminal activity to take place.

\section{c) Capabilities, Life Satisfaction and Gender Differences}

In this third and final analysis we employ all 60 plus capability indicators to model life satisfaction. As we noted, if happiness depends on what people do or are, then it should also depend on what it is they are free to do or be. Alternatively, one could argue that our analysis amounts to testing which capabilities matter most to the population from which our sample respondents are drawn - and that the significant capabilities are those which utilitarians would prioritise - because they affect people's welfare. Such capabilities would certainly be interesting because they are of importance both to advocates of the capabilities approach, and to defenders of traditional utilitarian approaches to welfare.

In column one of Table 3a, we present results of a regression model that was derived, by backwards elimination starting with all 60 plus indicators to arrive at a model with 17 in which all are significant covariates of happiness. Self-assessed life expectancy is not a significant correlate of life satisfaction (mirroring results elsewhere - see for instance Deaton (2007)) but the results show, nevertheless, that a wide range of capability dimensions are significant correlates of happiness. GHOLIDAY and BSHELTER, to do with the ability to afford a week's annual holiday or live in adequate accommodation could arguably both be taken as indicators of income, but this is less true of the remaining 15 indicators that cover issues that might broadly be described as abilities to socialise, live autonomously, be respected and use skills and talents. There has been much debate within economics about whether income brings happiness and if so under what circumstances and our finding seems rather clearly to support those who, like Sen, have argued that material status is only one factor amongst many that determines human welfare.

To explore the robustness of this finding, we add in a variety of controls (see rest of Table 3a) - similar results are obtained for the ordered logit and ordered probit models but we follow 
the practice of presenting the OLS versions to facilitate interpretation of results. We do not have panel data, which would allow for person specific controls but do have data on what psychologists call the big-five dimensions of personality and it is apparent, that the patterns of coefficient significance do not change much when these controls are added in. The same can be said for the fits obtained for the more general models. Happiness according to this picture is a function of a variety of dimensions of what people are able to do, and income seems only to play a limited role.

One further analysis worth remarking on concerns model estimation for subpopulations. Table $3 \mathrm{~b}$ presents the results for the data partitioned by gender and could be seen either as contributing to our assessment of robustness, or substantively, as contributing to the exploration of gender differences in the capabilities happiness relationship. In general the signs of coefficients are the same for men and women though the pattern of significant coefficients has notable differences. Particularly obvious is the fact that BSHELTER is significant for women but not men which could reflect a biologically oriented difference. However, when we examine a similar de-pooled exercise the coefficient is only significant for young people which in turn suggests that it is younger women who are particular sensitive to accommodation quality possibly because of their proximity to concerns about the implications that it has for child-rearing. Almost equally striking is the fact that experiencing racial discrimination at work in the past is significant for men but not for women, a result that is consistent with a number of possibilities that we cannot separate out. For example, it could be that discrimination is more severe for men than for women, but equally it could be that it is merely more salient for men, perhaps because they are less likely to suffer from other forms of discrimination, like gender, at work. Alternatively, it could be that racial discrimination at work is something men experience for longer as their workforce participation rates are higher. Clearly there are differences between men and women but combined with the fact that some variables like FROLE, measuring abilities to play a useful role in life, which are significant covariates of happiness for both men and women, suggest that where there are differences they are determined by environmental factors and that there are levels of abstraction at which concepts are equally significant between the sexes. Clearly these practical issues are rather important for designing and interpreting empirical work and indicate the need for additional inputs when one is trying to operationalise a theory such as that developed in Sen (1985).

\section{Concluding Remarks}

The chapter reports on a research project in which economists, philosophers and psychologists have sought to address the purported dearth of information about people's 
capabilities and use the data developed to assess welfare. The capabilities approach has already been highly influential in shaping the evolution of HDI and in this programme of work, we have focussed on developing and analysing instruments that could, in principle, be used to broaden its scope significantly. The research reported here illustrates the feasibility though non-triviality of the tasks involved and has highlighted a number of statistical issues though a number remain. Below we summarise the more significant points.

Firstly, it is important to recognise that both capabilities and subjective well-being maybe multi-dimensional. Here, we have shown how many of the more significant dimensions of capability can be measured but it is worth acknowledging that these capability indicators may be particularly closely related to satisfactions with particular areas of life. Our work on violence is related. Capabilities are inherently multi-dimensional but in looking at experiences of violence, we were able to isolate one set of capabilities and infer how it impacts on overall wellbeing, how it spreads to other dimensions and culminates in a relative wellbeing deprivation. This highlights the fact that capabilities can be operationalised in different ways: a global perspective sees how dimensions are intertwined whilst a partial perspective analyses the total effect, in a single area only. Beyond the research discussed here, such analyses remain largely unexplored at this point though it is worth highlighting the existence of work Kuklys (2005) in which she demonstrates how satisfaction with financial income can be used to generate econometric estimates of the cost of disability.

Secondly, we have highlighted the importance, and practical measurability, of personality. If there is heterogeneity between people in terms of the rate at which they convert resources into welfare, then personality is likely to be a significant contributor to variations in these conversion factors and we have shown how these can be partially treated in the absence of panel data. Thirdly, we have begun to explore the causes of capabilities though clearly there is further work to be done. Fourthly, we have shown that latent variable methods, traditionally used in statistics but increasingly employed in economics can play a valuable role in helping to understand patterns in observations that would otherwise be hard to detect by virtue of the high number of dimensions on which human capabilities can vary. Fifthly and finally, we have presented linear additive models of subjective wellbeing although some philosophical characterisations suggest that a lexicographic approach would be more appropriate. However, our additive models, used widely in empirical work, appear to serve quite well and this in turn suggests a piecemeal approach to policy could be feasible - even if one cannot address all sources of impoverishment and misery, addressing some will help. 
There remain areas of application where further questions could be devised but the questions developed and analysed to date nonetheless illustrate the economic statistics that the capabilities approach requires for its operationalisation within quantitative empirical work. In many cases, the empirical associations are not what one would immediately expect and while we have suggested possible explanations, they must be speculative. However, these surprising quantitative associations are useful in that they suggest ways of developing theory and pursuing related psychological investigations, quantitative or otherwise. 
References

Alkire S, 2002 Dimensions of Human Development, World Development, 30, 119-205

Anand P and van Hees M, 2006, Capabilities and Achievements, Journal of SocioEconomics, 35, 268-84

Anand P and Dolan P, 2005, Equity Capabilities and Health: Special Issue Introduction, Social Science and Medicine, 60, 219-222

Anand P, Hunter G and Smith R, 2005, Capabilities and Wellbeing: Evidence Based on the Sen-Nussbaum Approach to Welfare, Social Indicators Research, 79, 9-55

Anand P Hunter G Dowding K, Guala F, van Hees M, 2005, The Measurement of Human Capabilities, Milton Keynes, Open University Discussion Paper

Anand P and Santos C, 2007, Violence, Gender Inequalities and Life Satisfaction, Révue d'Économie Politique, 117, 135-60

Anand P and Wailoo A, 2000, Utilities vs. Rights to Publicly Provided Goods: Arguments and Evidence from Health Care Rationing, Economica, 67, 543-578

Brandolini, A and D’Alessio G, 1998, Measuring Wellbeing in the Functioning Space, plenary paper given to the $13^{\text {th }}$ International Economics Association Congress, Buenos Aires

Burchardt $\mathrm{T}$ and Le Grand, 2002, Constraint and Opportunity: Assessing Employment Capability, ESRC Research Centre for the Analysis of Social Exclusion, London School of Economics

Brower W B F, va Exel N Job A, and Stolk E A, 2004, Acceptability of Less Than Perfect Health States, (in Special Issue on Equity, Capabilities and Health) Social Science and Medicine, 60, 237-46

Carter I, 1999, A Measure of Freedom, Oxford, Oxford University Press 
Carter I, 2003, Functionings Capabilities and the Non-specific Value of Freedom, mimeo, Nuffield College, Oxford

Chiappero-Martinetti E, 2000, A Multi-dimensional Assessment of Wellbeing Based on Sen's Functioning Approach, Rivista Internazionale di Scienze Sociali, 107, 208-39

Clark A, Etile F, Postel-Vinay F, Senik C, van der Straeten K, 2005, Heterogeneity in Reported Wellbeing, The Economic Journal, 115, 118-32

Clark D A, 2003, Concepts and Perceptions of Human Wellbeing: Some Evidence from South Africa, Oxford Development Studies, 31, 173-196

Clark A E Frijters P and Shields M A. 2006, Income and Happiness: Evidence, explanations and economic implications, Paris-Jourdan Sciences Economiques, Working Paper $2006-24$

Di Tella R, Haisken-De New and MacCulloch R, 2007, Happiness Adaptation to Income and to Status in an Individual Panel, NBER, Cambridge Ma., Working Paper 13159

Everitt B S and Dunn G, 2001, Applied Multivariate Data Analysis, London, Hodder Arnold

Frey B and Stutzer A, 2000, Happiness, Economy and Institutions, Economic Journal, 110, 918-38

Gaertner $\mathrm{W}$ and Younsheng $\mathrm{Xu}, 2005$, Alternative Proposals to Measure the Standard of Living when its Development over Time is Uncertain, paper given to the American Economic Association Conference

Gosling S D and Rentfrow W B S, 2003, A very brief measure of the Big-Five personality domains, Journal of Research in Personality, 37, 504-28

van Hees M 2004, Freedom of Choice and Diversity of Options: Some Difficulties, Social Choice and Welfare, 22, 253-66

Helliwell JF. 2006, Wellbeing, Social Capital and Public Policy, Economic Journal, c35-45 
Kahneman D, Wakker P P and Sarin R, 1997, Back to Bentham? Explorations of Experienced Utility, Quarterly Journal of Economics, 112, 375-406

Kahneman D, Kruger A B, Schkade D, Schwarz N and Stone A, 2004, Toward National Wellbeing Accounts, American Economic Review, 94, 429-34

Kuklys W, 2005, Amartya Sen's Capability Approach: Theoretical Insights and Empirical Applications (Studies in Choice and Welfare), Berlin, Springer-Verlag

Kuklys W and Robeyns I, 2005, Sen’s Capability Approach to Welfare Economics, paper given to the Annual American Economic Association Conference

Laderchi C R, 2001, Do Concepts Matter? An Empirical Investigation of the Differences Between a Capability Approach and a Monetary Assessment of Poverty, Discussion Paper, Queen Elizabeth House, Oxford University

Layard R, 2005, Happiness: Lessons from a New Science, London, Allen Lane

Layte R, Nolan B and Whelan C T, 2000, Targeting Poverty: Lessons from Monitoring Ireland's National Anti-Poverty Strategy, Journal of Social Policy, 29, 553-75

Manski C F, 2004, Measuring Expectations, Econometrica, 72, 1329-1376

Nehring K and Puppe C, 2002, A Theory of Diversity, Econometrica, 70, 1155-98

Nussbaum M C, 2000, Women and Human Development: The Capabilities Approach, Cambridge, Cambridge University Press

Nussbaum M and Sen A K, 1993, The Quality of Life, Oxford, Clarendon Press

Oswald A J, 1997, Happiness and Economic Performance, Economic Journal, 107, 18151831

Pattanaik P and Xu Y, 1998, On Preference and Freedom, Theory and Decision, 44, 173-98

Qizilbash M, 2004, On the Arbitrariness and Robustness of Multi-dimensional Poverty Rankings, UNU Wider Research Paper 2004/37 and University of East Anglia 
Schokkaert E and van Ootegem L 1990, Sen's Concept of the Living Standard applied to the Belgium Unemployed, Recherches Economiques de Louvain, 56, 429-50

Robeyns I 2005, Selecting Capabilities for Quality of Life Measurement, Social Indicators Research, forthcoming

Sen A K, 1979, Personal Utilities and Public Judgements: Or What's Wrong with Welfare Economics, Economic Journal, 89, 537-58

Sen A K, 1985 Commodities and Capabilities, Amsterdam, North-Holland

Sen A K, 2006, Identity and Violence: the Illusion of Destiny, London, Allen Lane

Winkelmann L and Winkelmann R, 1998, Why are the Unemployed So Unhappy? Economica, 65, 1-15 


\title{
Appendix: Capabilities, Questions and Variables
}

\author{
Main Corresponding Question(s)
}

Variable Name and

Response Code

1. Given your family history, dietary habits, lifestyle and health status, until what age do you expect to live?

2. Does your health in any way limit your daily activities compared to most people of your age?

3. Are you able to have children?

4. Do you eat fresh meat, chicken or fish at least twice a week?

5 . Is your current accommodation adequate or inadequate for your current needs?

6. Are you prevented from moving home for any reason?

7. Please indicate how safe you feel walking alone in the area near your home during the daytime?

8. Please indicate how safe you feel walking alone in the area near your home after dark

9. Have you ever been the victim of some other form of violent assault or attack?

10. How likely do you think it is that you will be a victim of violent assault or attack in the future?

11. Have you ever been a victim of sexual assault?

12. Please indicate how vulnerable you feel to sexual assault or attack

13. Have you ever been a victim of domestic violence?

14. Please indicate how vulnerable you feel to domestic violence in the future.

15. Do you have sufficient opportunities to satisfy your sexual needs?

16. Even if you don't need or have never needed any of the following [contraception, abortion or infertility treatment], are you prohibited from using any of the following for any reason (eg religious beliefs, family pressure)?

17. What is the highest educational or work related qualification you have?

18. How often do you use your imagination and or reasoning in your day to day life?

19. I am free to express my political views.

20. I am free to practice my religion as I want to.

21. Have you recently been able to enjoy your normal day to day activities?

22. How difficult do you find it to make friendships which last with people outside work?

23. At present, how easy or difficult do you find it to enjoy the love care and support of your immediate family?

24. Do you find it easy or difficult to express feelings of love, grief, longing, gratitude and anger compared to most people of your age?

25 . Have you recently lost much sleep over worry?

26. Have you recently felt constantly under strain?

27. My idea of a good life is based on my own judgement.

28. I have a clear plan of how I would like my life to be.

29. How often, if at all, do you evaluate how you lead your life and where you are going in life?

30. Outside of work, have you recently felt that you were playing a useful part in things?

BHEALTH $=1$ if $\mathrm{N}, 0$

BPEPRODT $=0$ if $\mathrm{Y}$ or $\mathrm{N}^{*}$,

BNOURISH $=1$ if $\mathrm{Y}$ or $\mathrm{N}^{*}$,

ALIFEXP $=$ years

BSHELTER $=1$ if $\mathrm{A}, 0$

BCANMOVE $=0$ if $\mathrm{Pa}, 0$

CSAFEDAY = 1-7(Cs)

CSAFENYT $=1-7(\mathrm{Cs})$

CVASALPT $1=Y, 0$

CVASALTF $=1-7(E l)$

CSASALTP $1=\mathrm{Y}, 0$

CSASALTF $=1-7(\mathrm{El})$

CDASALPT $1=\mathrm{Y}, 0$

CDASALPF $=1-7(\mathrm{Vv})$

CSEXSAT $1=Y, 0$

CCHOICE 1=Y,0

DQUAL $1=\mathrm{A}+, 0$

DIMAGINE $=1-7(\mathrm{At})$

DXPRSPOL $=1-7$ (As)

DXPRSRLG $=1-7($ As $)$

DENDJOY2 = 1-4(Mu)

EFRIENDS $=1-7(\mathrm{Ee})$

ELOVE $=1-7(\mathrm{Ee})$

EFEELING $=1-7($ Ee $)$

ENOSLEEP $=1-4(\mathrm{Mu})$

ESTRAIN $=1-4(\mathrm{Mu})$

FGOOD $=1-7($ As $)$

FPLAN $=1-7$ (As)

FEVALUATE = 1-7(Att)

FROLE $=1-4(\mathrm{Mu})$ 
31. I respect, value and appreciate other people.

32. Do you normally have at least one week's (seven days) annual holiday away from home?

33. Do you normally meet up with friends or family for a drink or a meal at least once a month?

34. Do you tend to find it easy or difficult to imagine the situation of other people (ie to put yourself in others shoes)?

35. Have you recently been thinking of yourself as a worthless person?

36-41 Outside of any employment or work situation, have you ever

experienced discrimination because of your race, sexual orientation, gender, religion, age?

42-46 Outside of any employment or work situation, do you think is it that in the future you will be discriminated against because of your race, sexual orientation, gender, religion, age?

47. I appreciate and value plants, animals and the world of nature.

48. Have you recently been enjoying your recreational activities?

49. I am able to participate in the political activities that affect my life if I want to.

50. For which of the following reasons, if any, have you not bought your home? [ $\mathrm{U}=$ forced not for reasons or affordability or difficulty obtaining mortgage, 1 = home owner or chose not to buy for other reasons.] 51-55. When seeking work in the past, have you ever experienced discrimination because of your race, sexual orientation, gender, religion, age?

56-60. When seeking work in the future, how likely do think it is that you will experience discrimination because of you race, sexual orientation, gender, religion, age?

61 How likely do you think it is that within the next 12 months you will be stopped and search by the police when it is not warranted?

62. To what extent does your work make use of your skills and talents?

63. At work, have you recently felt that you were playing a useful part in things?

64. Do you tend to find it easy or difficult to relate to your colleagues at work?

65. At work, are you treated with respect?

GCONCERN = 1-7(As)

GHOLIDAY $=1$ if $Y, 0$

GMEAL $=1$ if $\mathrm{Y}, 0$

GIMAGINE = 1-7(Ee)

GWORTH $=1-4(\mathrm{Na})$

GRACEP $=0$ if $\mathrm{N}, 0$

$\mathrm{GSEXOP}=0$ if $\mathrm{N}, 0$

GGENP $=0$ if $N, 0$

GRELIGNP $=0$ if $\mathrm{N}, 0$

GAGEP $=0$ if $\mathrm{N}, 0$

GRACEF $=1-7(\mathrm{Eu})$

GSEXOF $=1-7(\mathrm{Eu})$

GGENF $=1-7(\mathrm{Eu})$

GRELIGNF $=1-7(\mathrm{Eu})$

$\mathrm{GAGEF}=1-7(\mathrm{Eu})$

HSPECIES = 1-7(As)

IPLAY = 1-4(Mu)

JPARTPOL $=($ As $)$

$\mathrm{JOWN}=0$ if $\mathrm{U}, 1$

JRACEWP $=1$ if $Y, 0$

JSEXOWP $=1$ if $Y, 0$

JGENDWP $=1$ if $Y, 0$

JRLIGNWP $=1$ if $Y, 0$

JAGEWP $=1$ if $Y, 0$

JRACEWF $=1-7(\mathrm{Eu})$ or $0 * *$

JSEXOWF $=1-7(\mathrm{Eu})$ or $0 * *$

JGENDWF $=1-7(\mathrm{Eu})$ or $0 * *$

JRLIGNWF $=1-7(\mathrm{Eu})$ or

$0 * *$

JAGEWF $=1-7(\mathrm{Eu})$ or $0 * *$ JSEARCH $=1-7(\mathrm{Eu})$ or $0 * *$

$\mathrm{JSKILLSW}=1-7(\mathrm{At})$ or $0 * * *$

JROLEW $=1-4(\mathrm{Mu})$ or $0 * * *$

JREALTEW = 1-7(Ee) or $0 * * *$

JRESPECTW $=1-7(\mathrm{At})$ or

Note

1. The terms 1-4, 1-7 indicate 4 four and 7 point scales and attached to each maximum is an abbreviation denoting the semantic anchor used for that point.

Key

$\mathrm{N}=$ No, $\mathrm{Y}=$ Yes, $\mathrm{N}^{*}=$ No for reasons of choice, $\mathrm{A}=$ Adequate, $\mathrm{Pa}=$ Prevented for reasons of affordability, $\mathrm{Cs}=$ Completely satisfied, El=Extremely likely, $\mathrm{Vv}=$ Very vulnerable, A+=A Level or above, As=Agree Strongly, $\mathrm{Mu}=$ Much more usual than often, $\mathrm{At}=\mathrm{All}$ the time, $* *$ indicates variable $=0$ if there is an intention to work in future (MDSWORKF $=1,0$ if there is no such intention), $* * *$ indicates variable $=$ 0 if the respondent is in work (MWORK=1, 0 if out of work). 
Table 1a Fit Diagnostics for Five Latent Class Models

\begin{tabular}{|c|c|c|c|c|c|c|}
\hline $\begin{array}{c}\text { No of Latent } \\
\text { Classes }\end{array}$ & LL & $\begin{array}{c}\text { Bayesian } \\
\text { Information } \\
\text { Criteria }\end{array}$ & $\begin{array}{c}\text { No of } \\
\text { parameters }\end{array}$ & L2 & df & p value \\
\hline 5 & -42505.08 & 87706.27 & 397 & 72921.78 & 493 & $2.7 \mathrm{e}-15197$ \\
\hline 6 & -42274.42 & 87598.09 & 449 & 72460.46 & 441 & $8.7 \mathrm{e}-15155$ \\
\hline 7 & -42130.72 & 87663.84 & 501 & 72173.06 & 389 & $4.9 \mathrm{e}-15151$ \\
\hline 8 & -42130.72 & 87786.53 & 553 & 71942.61 & 337 & $5.0 \mathrm{e}-15161$ \\
\hline 9 & -41813.26 & 87853.59 & 605 & 71656.52 & 285 & $1.1 \mathrm{e} 15160$ \\
\hline
\end{tabular}

Table 1b Wald Statistics for Health Status and Other Predictors of Latent Class Membership in a Six Class Model

\begin{tabular}{|c|c|c|c|c|c|c|}
\hline Covariate & \multicolumn{6}{|c|}{ Model Diagnostic Statistics } \\
\hline Health Status & $\begin{array}{c}51.97, \\
5.50 \mathrm{e}-10\end{array}$ & & $\begin{array}{l}\text { 31.5533, } \\
\text { 7.30e-06 }\end{array}$ & $\begin{array}{l}42.5177, \\
4.60 \mathrm{e}-08\end{array}$ & $\begin{array}{c}25.6563, \\
0.0001\end{array}$ & $\begin{array}{l}\text { 30.7661, } \\
1.00 \mathrm{e}-05\end{array}$ \\
\hline $\begin{array}{l}\text { Household } \\
\text { Income }\end{array}$ & & $\begin{array}{l}31.0012, \\
9.30 \mathrm{e}-06 \\
\end{array}$ & $\begin{array}{l}21.9757, \\
0.00053 \\
\end{array}$ & $\begin{array}{l}26.8417, \\
6.10 \mathrm{e}-05 \\
\end{array}$ & $\begin{array}{c}12.0814, \\
0.034 \\
\end{array}$ & $\begin{array}{l}20.9303, \\
0.00083 \\
\end{array}$ \\
\hline $\begin{array}{l}\text { Controls for } \\
\text { Age }\end{array}$ & \multicolumn{3}{|c|}{ No } & \multicolumn{3}{|c|}{ Yes } \\
\hline $\begin{array}{l}\text { Personality: } \\
\text { pagree } \\
\text { pconsc } \\
\text { popen } \\
\text { pstable } \\
\text { pxtravt }\end{array}$ & & & & & $\begin{array}{c}29.036,2.3 \mathrm{e}-05 \\
24.1576,0.0002 \\
55.0846, .3 \mathrm{e}-10 \\
49.8809,1.50 \mathrm{e}-09 \\
19.8605,0.0013\end{array}$ & $\begin{array}{c}29.3056,2.00 \mathrm{e}-05 \\
21.8305,0.00056 \\
60.14,1.10 \mathrm{e}-11 \\
50.2556,1.20 \mathrm{e}-09 \\
24.708,0.00016\end{array}$ \\
\hline $\begin{array}{l}\text { Controls for } \\
\text { Regions }\end{array}$ & \multicolumn{5}{|c|}{ No } & Yes \\
\hline
\end{tabular}

Notes

Cell entries indicate the value of the Wald statistic and its associated p value respectively. Controls for age comprise age and its square. Coefficients for all models in Table 3 are available on request. 
Table 1c Average Covariate Characteristics by Class

\begin{tabular}{|l|c|c|c|c|c|c|}
\hline & Class 1 & Class 2 & Class 3 & Class 4 & Class 5 & Class 6 \\
\hline $\begin{array}{l}\text { Class size } \\
\text { \% of sample) }\end{array}$ & $23.7 \%$ & $20.79 \%$ & $19.05 \%$ & $18.30 \%$ & $10.13 \%$ & $8.02 \%$ \\
\hline Health Status & $78.49 \%$ & $82.96 \%$ & $85.74 \%$ & $61.45 \%$ & $67.95 \%$ & $47.01 \%$ \\
\hline mghi & 3.19 & 3.31 & 3.33 & 2.93 & 2.86 & 2.32 \\
\hline pagreeable & 4.73 & 4.88 & 5.50 & 4.93 & 5.23 & 4.41 \\
\hline pconscientious & 5.12 & 5.53 & 5.87 & 4.9 & 5.42 & 4.7 \\
\hline popen & 4.86 & 4.58 & 5.36 & 4.60 & 5.55 & 5.22 \\
\hline pstable & 4.47 & 4.87 & 5.32 & 3.61 & 4.70 & 3.41 \\
\hline pextravert & 4.09 & 4.07 & 4.84 & 3.53 & 4.14 & 3.51 \\
\hline mage & 42.19 & 46.17 & 50.63 & 39.65 & 47.14 & 38.14 \\
\hline mmale & $59.73 \%$ & $54.22 \%$ & $45.55 \%$ & $40.73 \%$ & $10.64 \%$ & $38.41 \%$ \\
\hline mrmidwls & $25.05 \%$ & $29.76 \%$ & $20.58 \%$ & $18.30 \%$ & $18.99 \%$ & $13.47 \%$ \\
\hline mrnorth & $25.15 \%$ & $28.93 \%$ & $28.50 \%$ & $24.78 \%$ & $32.82 \%$ & $38.71 \%$ \\
\hline mrscot & $10.25 \%$ & $8.05 \%$ & $10.64 \%$ & $12.77 \%$ & $7.02 \%$ & $3.45 \%$ \\
\hline mrsouth & $16.61 \%$ & $21.57 \%$ & $27.10 \%$ & $24.48 \%$ & $13.09 \%$ & $29.58 \%$ \\
\hline
\end{tabular}


Table 2a: Self-Reported Experience of Violence by Gender

Proportion Females

0.151

Sexual Assault (SA)

Domestic Violence (DV)

0.226

0.062

0.123
Proportion Males

0.048

0.099

0.015

0.339 p-value

0.000

0.000

0.000

0.000

$t$-test on the equality of means, where data is not assumed to be paired.

Table 2b: Self-Reported Violence-Related Capabilities by Gender

\begin{tabular}{llllll} 
& Females & \multicolumn{1}{c}{ Males } & Median & $p$-value \\
& Mean & Median & Mean & 2 & 0.000 \\
Fear During Day (D) & 2.155 & 2 & 1.925 & 3 & 0.000 \\
Fear at Night (N) & 3.670 & 3 & 2.785 & 1 & 0.000 \\
Vulnerability to Sexual Assault (VSA) & 3.439 & 3 & 1.535 & 1 & 0.000 \\
Vulnerability to Domestic Violence (VDV) & 1.585 & 1 & 1.328 & 3 & 0.990
\end{tabular}

Wilcoxon rank-sum test on the equality of the distributions. 
Table 2c: Identifying the Relatively Vulnerable: Probit Models of Reported Experiences of Violence by Gender

\begin{tabular}{|c|c|c|c|c|c|c|}
\hline & & Females & & & Males & \\
\hline & SA & DV & VA & SA & DV & VA \\
\hline$[35,55[$ years old & 0.059 & 0.185 & 0.221 & -0.161 & 0.302 & 0.105 \\
\hline & $(0.212)$ & $(0.192)$ & $(0.225)$ & $(0.396)$ & $(0.299)$ & $(0.209)$ \\
\hline$>=55$ years old & 0.123 & 0.304 & -0.094 & -0.319 & 0.094 & -0.249 \\
\hline & $(0.232)$ & $(0.216)$ & $(0.257)$ & $(0.456)$ & $(0.390)$ & $(0.254)$ \\
\hline Separated & 0.003 & 0.503 & $0.694^{*}$ & 0.278 & $0.895 *$ & 0.087 \\
\hline & $(0.288)$ & $(0.259)$ & $(0.277)$ & $(0.408)$ & $(0.360)$ & $(0.318)$ \\
\hline No Partner & -0.007 & -0.070 & 0.300 & -0.898 & 0.135 & 0.218 \\
\hline & $(0.218)$ & $(0.202)$ & $(0.232)$ & $(0.484)$ & $(0.364)$ & $(0.221)$ \\
\hline$[10000,20000[$ household income & 0.118 & -0.440 & -0.043 & -0.867 & 0.231 & 0.031 \\
\hline & $(0.291)$ & $(0.263)$ & $(0.287)$ & $(0.533)$ & $(0.435)$ & $(0.371)$ \\
\hline [20000,30000[ household income & -0.290 & $-0.809 * *$ & 0.153 & -0.816 & -0.125 & -0.090 \\
\hline & $(0.325)$ & $(0.275)$ & $(0.311)$ & $(0.661)$ & $(0.524)$ & $(0.405)$ \\
\hline$>=30000$ household income & -0.287 & $-0.663^{*}$ & 0.023 & $-1.716^{* *}$ & 0.025 & 0.174 \\
\hline & $(0.333)$ & $(0.299)$ & $(0.330)$ & $(0.605)$ & $(0.566)$ & $(0.420)$ \\
\hline$[10000,20000[$ individual income & -0.095 & 0.297 & -0.196 & 0.609 & -0.400 & 0.124 \\
\hline & $(0.226)$ & $(0.214)$ & $(0.253)$ & $(0.497)$ & $(0.362)$ & $(0.309)$ \\
\hline [20000,30000[ individual income & -0.452 & 0.462 & -0.175 & 0.006 & -0.454 & -0.129 \\
\hline & $(0.330)$ & $(0.278)$ & $(0.296)$ & $(0.642)$ & $(0.451)$ & $(0.364)$ \\
\hline$>=30000$ individual income & 0.352 & -0.001 & -0.362 & 0.728 & -0.691 & -0.353 \\
\hline & $(0.347)$ & $(0.376)$ & $(0.430)$ & $(0.654)$ & $(0.548)$ & $(0.406)$ \\
\hline Non-White British & -0.265 & 0.379 & -0.075 & (dropped) & 0.439 & 0.343 \\
\hline & $(0.329)$ & $(0.264)$ & $(0.300)$ & & $(0.316)$ & $(0.275)$ \\
\hline At least 1 child & -0.174 & 0.068 & -0.389 & -0.208 & 0.304 & 0.257 \\
\hline & $(0.221)$ & $(0.191)$ & $(0.216)$ & $(0.352)$ & $(0.288)$ & $(0.192)$ \\
\hline Vocational Diploma & 0.362 & 0.101 & 0.529 & -0.166 & -0.217 & -0.055 \\
\hline & $(0.310)$ & $(0.284)$ & $(0.394)$ & $(0.354)$ & $(0.355)$ & $(0.270)$ \\
\hline CSE A Level & 0.081 & 0.148 & 0.152 & (dropped) & -0.411 & -0.245 \\
\hline & $(0.308)$ & $(0.267)$ & $(0.376)$ & & $(0.350)$ & $(0.269)$ \\
\hline Graduate & 0.231 & -0.231 & 0.355 & -0.077 & -0.152 & -0.103 \\
\hline & $(0.309)$ & $(0.288)$ & $(0.389)$ & $(0.394)$ & $(0.352)$ & $(0.285)$ \\
\hline Not employed (at home) & 0.288 & -0.012 & 0.002 & -0.045 & -0.200 & -0.177 \\
\hline & $(0.199)$ & $(0.181)$ & $(0.217)$ & $(0.344)$ & $(0.296)$ & $(0.226)$ \\
\hline Extraversion & -0.063 & -0.165 & -0.212 & -0.081 & -0.258 & -0.179 \\
\hline & $(0.124)$ & $(0.104)$ & $(0.128)$ & $(0.152)$ & $(0.136)$ & $(0.097)$ \\
\hline Agreeableness & $0.180^{*}$ & $0.235 * *$ & $0.257 * *$ & 0.082 & $0.248 *$ & 0.068 \\
\hline & $(0.090)$ & $(0.087)$ & $(0.099)$ & $(0.134)$ & $(0.121)$ & $(0.082)$ \\
\hline Conscientiousness & -0.028 & 0.013 & 0.150 & -0.023 & 0.183 & $0.279 * *$ \\
\hline & $(0.096)$ & $(0.090)$ & $(0.100)$ & $(0.153)$ & $(0.120)$ & $(0.091)$ \\
\hline Emotional Stability & -0.181 & -0.025 & -0.064 & -0.065 & -0.112 & -0.031 \\
\hline & $(0.095)$ & $(0.095)$ & $(0.112)$ & $(0.156)$ & $(0.121)$ & $(0.093)$ \\
\hline Openness & -0.075 & 0.007 & -0.020 & -0.209 & -0.085 & -0.048 \\
\hline & $(0.095)$ & $(0.085)$ & $(0.097)$ & $(0.150)$ & $(0.115)$ & $(0.090)$ \\
\hline Local Crime Rates & 0.009 & -0.008 & -0.001 & 0.006 & -0.005 & 0.004 \\
\hline & $(0.007)$ & $(0.007)$ & $(0.008)$ & $(0.004)$ & $(0.007)$ & $(0.005)$ \\
\hline South of England exc. London & -0.024 & -0.053 & -0.363 & 0.528 & 0.050 & -0.314 \\
\hline & $(0.278)$ & $(0.255)$ & $(0.264)$ & $(0.431)$ & $(0.285)$ & $(0.236)$ \\
\hline Midlands and Wales & 0.109 & 0.389 & - & 0.190 & $-1.224^{* *}$ & -0.415 \\
\hline & $(0.260)$ & $(0.244)$ & $(0.274)$ & $(0.524)$ & $(0.399)$ & $(0.231)$ \\
\hline North of England & 0.043 & 0.253 & -0.388 & -0.259 & -0.111 & -0.190 \\
\hline & $(0.247)$ & $(0.236)$ & $(0.245)$ & $(0.503)$ & $(0.270)$ & $(0.219)$ \\
\hline Constant & $-1.472 * *$ & -0.801 & $-1.253^{*}$ & -0.647 & -0.856 & -0.300 \\
\hline & $(0.485)$ & $(0.440)$ & $(0.516)$ & $(0.703)$ & $(0.638)$ & $(0.484)$ \\
\hline do $\mathrm{R}^{2}$ & 0.077 & 0.107 & 0.106 & 0.202 & 0.195 & 0.094 \\
\hline & 382 & 389 & 390 & 214 & 330 & 329 \\
\hline
\end{tabular}

Significance levels : *: $5 \% * *: 1 \% * * *: 0.1 \%$

Marginal effects reported. Standard errors in parentheses. All variables are described in the appendix. 
Reference categories are: <35 years old, married, Other schooling, [0,10000[ gross household income, [0,10000[ gross individual income, White British, no Dependent children, other schooling, working at least 8hrs/week and London. 
Table 2d: Ordered Probit Models of Well-Being Deprivation by Gender

\begin{tabular}{|c|c|c|c|c|}
\hline & \multicolumn{2}{|c|}{ Females } & \multicolumn{2}{|c|}{ Males } \\
\hline & Experience Only & Both & Experience Only & Both \\
\hline \multirow[t]{2}{*}{ Victim of Sexual Assault? } & -0.133 & -0.264 & 0.044 & 0.002 \\
\hline & $(0.170)$ & $(0.176)$ & $(0.312)$ & $(0.318)$ \\
\hline \multirow[t]{2}{*}{ Victim of Domestic Violence? } & $0.366^{*}$ & 0.275 & 0.240 & 0.260 \\
\hline & $(0.152)$ & $(0.160)$ & $(0.235)$ & $(0.250)$ \\
\hline \multirow[t]{2}{*}{ Victim of any other Form of Violence? } & 0.056 & -0.062 & -0.011 & -0.039 \\
\hline & $(0.189)$ & $(0.193)$ & $(0.149)$ & $(0.153)$ \\
\hline \multirow[t]{2}{*}{ Vulnerability to Sexual Assault } & & $0.290 * *$ & & 0.106 \\
\hline & & $(0.096)$ & & $(0.123)$ \\
\hline \multirow[t]{2}{*}{ Vulnerability to Domestic Violence } & & $0.302 * *$ & & -0.023 \\
\hline & & $(0.116)$ & & $(0.156)$ \\
\hline \multirow[t]{2}{*}{ Likelihood of Future Violence of any other } & & $0.290 * *$ & & 0.092 \\
\hline & & $(0.103)$ & & $(0.092)$ \\
\hline \multirow[t]{2}{*}{$35,55[$ years old } & 0.061 & 0.294 & -0.041 & -0.013 \\
\hline & $(0.156)$ & $(0.164)$ & $(0.186)$ & $(0.188)$ \\
\hline \multirow[t]{2}{*}{$>=55$ years old } & $-0.379 *$ & -0.053 & -0.314 & -0.250 \\
\hline & $(0.174)$ & $(0.186)$ & $(0.219)$ & $(0.223)$ \\
\hline \multirow[t]{2}{*}{ Separated } & 0.092 & 0.077 & 0.471 & 0.441 \\
\hline & $(0.227)$ & $(0.231)$ & $(0.275)$ & $(0.277)$ \\
\hline \multirow[t]{2}{*}{ No Partner } & $0.402 *$ & $0.404^{*}$ & $0.426 *$ & $0.429 *$ \\
\hline & $(0.165)$ & $(0.167)$ & $(0.194)$ & $(0.195)$ \\
\hline \multirow[t]{2}{*}{$10000,20000[$ household income } & -0.105 & -0.130 & -0.356 & -0.344 \\
\hline & $(0.225)$ & $(0.229)$ & $(0.317)$ & $(0.319)$ \\
\hline \multirow[t]{2}{*}{ [20000,30000[ household income } & 0.088 & 0.061 & $-0.702 *$ & -0.667 \\
\hline & $(0.235)$ & $(0.238)$ & $(0.347)$ & $(0.349)$ \\
\hline \multirow[t]{2}{*}{ >= 30000 household income } & -0.348 & -0.362 & -0.714 & -0.668 \\
\hline & $(0.253)$ & $(0.258)$ & $(0.368)$ & $(0.370)$ \\
\hline \multirow[t]{2}{*}{10000,20000 [ individual income } & 0.050 & 0.096 & -0.066 & -0.064 \\
\hline & $(0.173)$ & $(0.176)$ & $(0.263)$ & $(0.264)$ \\
\hline [20000,30000[ individual income & -0.303 & -0.276 & -0.227 & -0.254 \\
\hline & $(0.225)$ & $(0.229)$ & $(0.305)$ & $(0.305)$ \\
\hline$>=30000$ individual income & -0.102 & 0.008 & -0.344 & -0.386 \\
\hline & $(0.281)$ & $(0.287)$ & $(0.341)$ & $(0.342)$ \\
\hline Non-White British & 0.211 & 0.329 & $0.625^{*}$ & $0.593 *$ \\
\hline & $(0.226)$ & $(0.232)$ & $(0.268)$ & $(0.270)$ \\
\hline At least 1 child & -0.161 & -0.138 & 0.115 & 0.129 \\
\hline & $(0.158)$ & $(0.161)$ & $(0.168)$ & $(0.170)$ \\
\hline Vocational Diploma & -0.083 & -0.195 & 0.065 & 0.068 \\
\hline & $(0.238)$ & $(0.244)$ & $(0.243)$ & $(0.243)$ \\
\hline CSE A Level & -0.152 & -0.250 & -0.095 & -0.082 \\
\hline & $(0.229)$ & $(0.234)$ & $(0.247)$ & $(0.249)$ \\
\hline Graduate & -0.236 & -0.252 & -0.168 & -0.135 \\
\hline & $(0.237)$ & $(0.241)$ & $(0.253)$ & $(0.255)$ \\
\hline Not employed (at home) & 0.094 & 0.123 & -0.334 & -0.332 \\
\hline & $(0.152)$ & $(0.155)$ & $(0.189)$ & $(0.190)$ \\
\hline Extraversion & $-0.314^{* * *}$ & $-0.324 * * *$ & $-0.321 * * *$ & $-0.320 * * *$ \\
\hline & $(0.082)$ & $(0.084)$ & $(0.087)$ & $(0.087)$ \\
\hline Agreeableness & 0.119 & 0.089 & 0.061 & 0.052 \\
\hline & $(0.072)$ & $(0.073)$ & $(0.072)$ & $(0.072)$ \\
\hline Conscientiousness & -0.078 & -0.042 & 0.065 & 0.062 \\
\hline & $(0.076)$ & $(0.077)$ & $(0.077)$ & $(0.077)$ \\
\hline Emotional Stability & 0.060 & 0.052 & -0.023 & -0.021 \\
\hline & $(0.074)$ & $(0.076)$ & $(0.080)$ & $(0.081)$ \\
\hline Openness & -0.082 & -0.100 & -0.006 & 0.001 \\
\hline & $(0.070)$ & $(0.071)$ & $(0.077)$ & $(0.078)$ \\
\hline Local Crime Rates & -0.005 & -0.008 & -0.010 & $-0.011^{*}$ \\
\hline & $(0.006)$ & $(0.006)$ & $(0.006)$ & $(0.006)$ \\
\hline South of England exc. London & 0.244 & 0.376 & 0.059 & 0.065 \\
\hline & $(0.205)$ & $(0.211)$ & $(0.210)$ & $(0.210)$ \\
\hline
\end{tabular}




$\begin{array}{lcccc}\text { Midlands and Wales } & -0.407^{*} & -0.403^{*} & 0.259 & 0.243 \\ & (0.201) & (0.205) & (0.200) & (0.202) \\ \text { North of England } & -0.111 & -0.063 & 0.206 & 0.197 \\ & (0.194) & (0.198) & (0.193) & (0.194) \\ \text { Pseudo R2 } & 0.093 & 0.135 & 0.110 & 0.113 \\ \text { N } & 379 & 379 & 327 & 327\end{array}$

Significance levels : *: $5 \% * *: 1 \% * * *: 0.1 \%$

Standard errors in parentheses. All variables are described in the appendix.

Reference categories are: $<35$ years old, married, Other schooling, [0,10000[ gross household income, [0,10000[ gross individual income, White British, no Dependent children, other schooling, working at least 8hrs/week and London.

i Helliwell (2006).
ii Clark, Frijters and Shields (2006). 
Table 3a Regression of Subjective Well-being on Capabilities, with Demographics, and Personality Controls

\begin{tabular}{|c|c|c|c|c|c|c|c|c|c|c|c|c|c|c|c|c|}
\hline \multirow[b]{2}{*}{ Variable } & \multicolumn{4}{|c|}{ Capabilities } & \multicolumn{4}{|c|}{ Capabilities and Demographics } & \multicolumn{4}{|c|}{ Capabilities and Personality } & \multicolumn{4}{|c|}{ Capabilities, Demographics and Personality } \\
\hline & Coef. & Std.Error & t stat & $\mathrm{p}$ value & Coef. & Std.Error & t stat & $\mathrm{P}$ value & Coef. & Std.Error & t stat & $\mathrm{p}$ value & Coef. & Std.Error & t stat & $\mathrm{p}$ value \\
\hline BSHELTER & 0.27 & 0.09 & 2.93 & 0.00 & 0.29 & 0.10 & 2.99 & 0.00 & 0.22 & 0.09 & 2.37 & 0.02 & 0.23 & 0.09 & 2.43 & 0.02 \\
\hline CDASALTP & -0.17 & 0.08 & -2.01 & 0.04 & -0.13 & 0.09 & -1.53 & 0.13 & -0.17 & 0.08 & -2.03 & 0.04 & -0.14 & 0.09 & -1.69 & 0.09 \\
\hline CSEXSAT & 0.25 & 0.07 & 3.33 & 0.00 & 0.21 & 0.08 & 2.86 & 0.00 & 0.25 & 0.07 & 3.47 & 0.00 & 0.22 & 0.07 & 2.91 & 0.00 \\
\hline ELOVE & 0.08 & 0.03 & 3.03 & 0.00 & 0.08 & 0.03 & 2.94 & $\mathbf{0 . 0 0}$ & 0.08 & 0.03 & 3.16 & 0.00 & 0.08 & 0.03 & 2.99 & 0.00 \\
\hline EFEELING & 0.11 & 0.03 & 4.14 & 0.00 & 0.11 & 0.03 & 4.14 & 0.00 & 0.10 & 0.03 & 3.68 & 0.00 & 0.10 & 0.03 & 3.62 & 0.00 \\
\hline ESTRAIN & -0.13 & 0.04 & -3.24 & 0.00 & -0.10 & 0.04 & -2.48 & 0.01 & -0.11 & 0.04 & -2.72 & 0.01 & -0.08 & 0.04 & -2.09 & 0.04 \\
\hline FGOOD & 0.09 & 0.03 & 3.17 & 0.00 & 0.10 & 0.03 & 3.56 & 0.00 & 0.08 & 0.03 & 3.01 & 0.00 & 0.09 & 0.03 & 3.37 & 0.00 \\
\hline FEVALUATE & -0.06 & 0.03 & -2.15 & 0.03 & -0.06 & 0.03 & -2.16 & 0.03 & -0.03 & 0.03 & -1.23 & 0.22 & -0.03 & 0.03 & -1.22 & 0.22 \\
\hline FROLE & 0.36 & 0.05 & 6.89 & 0.00 & 0.38 & 0.05 & 7.35 & 0.00 & 0.35 & 0.05 & 6.72 & 0.00 & 0.37 & 0.05 & 7.15 & 0.00 \\
\hline GCONCERN & 0.09 & 0.03 & 2.69 & 0.01 & 0.12 & 0.04 & 3.26 & 0.00 & 0.11 & 0.04 & 3.01 & 0.00 & 0.13 & 0.04 & 3.38 & 0.00 \\
\hline GHOLIDAY & 0.27 & 0.08 & 3.28 & 0.00 & 0.21 & 0.09 & 2.49 & 0.01 & 0.25 & 0.08 & 3.08 & 0.00 & 0.20 & 0.08 & 2.35 & 0.02 \\
\hline GWORTH & 0.35 & 0.04 & 7.86 & 0.00 & 0.37 & 0.05 & 8.00 & 0.00 & 0.29 & 0.05 & 6.36 & 0.00 & 0.31 & 0.05 & 6.65 & 0.00 \\
\hline JRACEWP & -0.54 & 0.17 & -3.18 & 0.00 & -0.55 & 0.17 & -3.24 & 0.00 & -0.58 & 0.17 & -3.46 & 0.00 & -0.59 & 0.17 & -3.49 & 0.00 \\
\hline JRACEWF & 0.08 & 0.03 & 2.26 & 0.02 & 0.07 & 0.03 & 2.18 & 0.03 & 0.07 & 0.03 & 2.23 & 0.03 & 0.07 & 0.03 & 2.16 & 0.03 \\
\hline MDSWORKF & -0.23 & 0.09 & -2.41 & 0.02 & -0.25 & 0.10 & -2.43 & 0.02 & -0.24 & 0.09 & -2.61 & 0.01 & -0.28 & 0.10 & -2.74 & 0.01 \\
\hline JSEARCH & -0.05 & 0.02 & -2.20 & 0.03 & -0.04 & 0.02 & -1.70 & 0.09 & -0.06 & 0.02 & -2.38 & 0.02 & -0.04 & 0.02 & -1.75 & 0.08 \\
\hline MMALE & & & & & -0.04 & 0.07 & -0.61 & 0.54 & & & & & -0.08 & 0.07 & -1.06 & 0.29 \\
\hline MAGE & & & & & -0.02 & 0.01 & -1.64 & 0.10 & & & & & -0.02 & 0.01 & -1.41 & 0.16 \\
\hline MAGE2 & & & & & 0.00 & 0.00 & 1.38 & 0.17 & & & & & 0.00 & 0.00 & 1.12 & 0.26 \\
\hline MGHI & & & & & 0.07 & 0.03 & 2.40 & 0.02 & & & & & 0.06 & 0.03 & 2.09 & 0.04 \\
\hline MRSOUTH & & & & & -0.20 & 0.10 & -1.96 & 0.05 & & & & & -0.18 & 0.10 & -1.75 & 0.08 \\
\hline MRMIDWLS & & & & & 0.00 & 0.10 & -0.04 & 0.97 & & & & & 0.04 & 0.10 & 0.36 & 0.72 \\
\hline MRNORTH & & & & & -0.17 & 0.10 & -1.71 & 0.09 & & & & & -0.14 & 0.10 & -1.43 & 0.15 \\
\hline MRSCOT & & & & & -0.04 & 0.13 & -0.30 & 0.77 & & & & & 0.00 & 0.13 & 0.00 & 1.00 \\
\hline PXTRAVRT & & & & & & & & & 0.08 & 0.03 & 3.04 & 0.00 & 0.07 & 0.03 & 2.74 & 0.01 \\
\hline PAGREEBL & & & & & & & & & -0.04 & 0.03 & -1.41 & 0.16 & -0.04 & 0.03 & -1.17 & 0.24 \\
\hline PCONSCS & & & & & & & & & -0.04 & 0.03 & -1.54 & 0.13 & -0.03 & 0.03 & -1.22 & 0.22 \\
\hline PSTABLE & & & & & & & & & 0.11 & 0.03 & 4.19 & 0.00 & 0.12 & 0.03 & 4.42 & 0.00 \\
\hline POPEN & & & & & & & & & -0.04 & 0.03 & -1.16 & 0.25 & -0.03 & 0.03 & -1.02 & 0.31 \\
\hline $\mathrm{R}^{2}$ & 0.54 & & & & 0.55 & & & & 0.56 & & & & 0.57 & & & \\
\hline Adjusted $\mathrm{R}^{2}$ & 0.53 & & & & 0.54 & & & & 0.55 & & & & 0.55 & & & \\
\hline Log likelihood & -999.89 & & & & -990.71 & & & & -983.08 & & & & -974.19 & & & \\
\hline Observations & 778 & & & & 778 & & & & 778 & & & & 778 & & & \\
\hline
\end{tabular}


Table 3b. Model Estimates for Sub-samples by Gender

\begin{tabular}{|c|c|c|c|c|c|c|c|c|c|c|}
\hline \multirow[b]{2}{*}{ Variable } & \multicolumn{4}{|c|}{ Female } & \multirow[b]{2}{*}{$\begin{array}{r}\text { Ordered } \\
\text { Logit } \\
\text { p value }\end{array}$} & \multicolumn{4}{|c|}{ Male } & \multirow[b]{2}{*}{$\begin{array}{r}\text { Ordered } \\
\text { Logit } \\
\text { p value }\end{array}$} \\
\hline & $\begin{array}{l}\text { OLS } \\
\text { Coef }\end{array}$ & $\begin{array}{r}\text { Std } \\
\text { Error }\end{array}$ & t stat & p value & & $\begin{array}{l}\text { OLS } \\
\text { Coef }\end{array}$ & $\begin{array}{r}\text { Std } \\
\text { Error }\end{array}$ & t stat & p value & \\
\hline BSHELTER & 0.39 & 0.13 & 3.05 & 0.00 & 0.01 & 0.02 & 0.15 & 0.14 & 0.89 & 0.96 \\
\hline CDASALTP & -0.18 & 0.10 & -1.75 & 0.08 & 0.19 & -0.18 & 0.17 & -1.10 & 0.27 & 0.36 \\
\hline CSEXSAT & 0.14 & 0.11 & 1.29 & 0.20 & 0.09 & 0.29 & 0.11 & 2.70 & 0.01 & 0.00 \\
\hline ELOVE & 0.12 & 0.03 & 3.54 & 0.00 & 0.00 & 0.02 & 0.04 & 0.62 & 0.54 & 0.20 \\
\hline EFEELING & 0.04 & 0.04 & 1.00 & 0.32 & 0.38 & 0.16 & 0.04 & 3.91 & 0.00 & 0.00 \\
\hline ESTRAIN & -0.04 & 0.05 & -0.69 & 0.49 & 0.07 & -0.16 & 0.06 & -2.44 & 0.02 & 0.01 \\
\hline FGOOD & 0.16 & 0.04 & 3.93 & 0.00 & 0.00 & 0.05 & 0.04 & 1.37 & 0.17 & 0.44 \\
\hline FPLAN & 0.11 & 0.04 & 3.17 & 0.00 & 0.00 & 0.09 & 0.04 & 2.52 & 0.01 & 0.03 \\
\hline FEVALUATE & -0.03 & 0.04 & -0.90 & 0.37 & 0.48 & -0.02 & 0.04 & -0.62 & 0.54 & 0.70 \\
\hline FROLE & 0.41 & 0.07 & 5.91 & 0.00 & 0.00 & 0.30 & 0.08 & 3.64 & 0.00 & 0.00 \\
\hline GCONCERN & 0.13 & 0.05 & 2.60 & 0.01 & 0.03 & 0.08 & 0.06 & 1.32 & 0.19 & 0.30 \\
\hline GHOLIDAY & 0.12 & 0.11 & 1.09 & 0.28 & 0.37 & 0.27 & 0.14 & 2.00 & 0.05 & 0.02 \\
\hline GWORTH & 0.32 & 0.06 & 5.09 & 0.00 & 0.00 & 0.28 & 0.07 & 3.92 & 0.00 & 0.01 \\
\hline JRACEWP & -0.23 & 0.26 & -0.88 & 0.38 & 0.54 & -0.73 & 0.23 & -3.24 & 0.00 & 0.00 \\
\hline JRACEWF & 0.04 & 0.05 & 0.87 & 0.39 & 0.34 & 0.07 & 0.05 & 1.56 & 0.12 & 0.04 \\
\hline MDSWORKF & -0.40 & 0.14 & -2.89 & 0.00 & 0.00 & -0.11 & 0.15 & -0.73 & 0.47 & 0.23 \\
\hline JSEARCH & -0.03 & 0.04 & -0.87 & 0.38 & 0.11 & -0.05 & 0.03 & -1.37 & 0.17 & 0.02 \\
\hline JSKILLSW & 0.02 & 0.04 & 0.44 & 0.66 & 0.37 & 0.11 & 0.04 & 2.63 & 0.01 & 0.00 \\
\hline MWORK & -0.03 & 0.23 & -0.13 & 0.90 & 0.57 & -0.75 & 0.25 & -3.02 & 0.00 & 0.00 \\
\hline MAGE & -0.03 & 0.02 & -1.92 & 0.06 & 0.06 & 0.01 & 0.02 & 0.80 & 0.42 & 0.55 \\
\hline MAGE2 & 0.00 & 0.00 & 1.19 & 0.24 & 0.16 & 0.00 & 0.00 & -0.58 & 0.56 & 0.41 \\
\hline MGHI & 0.03 & 0.04 & 0.89 & 0.37 & 0.36 & 0.10 & 0.04 & 2.30 & 0.02 & 0.04 \\
\hline MRSOUTH & -0.16 & 0.14 & -1.14 & 0.25 & 0.20 & -0.17 & 0.15 & -1.14 & 0.26 & 0.17 \\
\hline MRMIDWLS & 0.14 & 0.14 & 0.99 & 0.32 & 0.34 & -0.11 & 0.15 & -0.71 & 0.48 & 0.30 \\
\hline MRNORTH & -0.13 & 0.13 & -1.00 & 0.32 & 0.45 & -0.12 & 0.14 & -0.82 & 0.41 & 0.23 \\
\hline MRSCOT & 0.13 & 0.18 & 0.73 & 0.47 & 0.74 & -0.12 & 0.18 & -0.63 & 0.53 & 0.47 \\
\hline PXTRAVRT & 0.08 & 0.03 & 2.39 & 0.02 & 0.02 & 0.03 & 0.04 & 0.78 & 0.44 & 0.53 \\
\hline PAGREEBL & -0.06 & 0.04 & -1.34 & 0.18 & 0.24 & 0.00 & 0.05 & -0.08 & 0.93 & 0.80 \\
\hline PCONSCS & -0.07 & 0.04 & -1.80 & 0.07 & 0.03 & 0.00 & 0.04 & 0.01 & 0.99 & 0.80 \\
\hline PSTABLE & 0.13 & 0.04 & 3.52 & 0.00 & 0.00 & 0.14 & 0.04 & 3.32 & 0.00 & 0.00 \\
\hline POPEN & -0.01 & 0.04 & -0.32 & 0.75 & 0.90 & -0.05 & 0.05 & -1.13 & 0.26 & 0.30 \\
\hline $\mathrm{R}^{2}$ & 0.61 & & & & & 0.58 & & & & \\
\hline Adjusted $\mathrm{R}^{2}$ & 0.58 & & & & & 0.54 & & & & \\
\hline Log likelihood & -505.9 & & & & & -445.0 & & & & \\
\hline Observations & 418 & & & & & 360 & & & & \\
\hline
\end{tabular}




\section{Key to Controls}

\section{Socio-Demographics}

$\begin{array}{ll}\text { MMALE } & \text { Gender (1=female, } 0=\text { male) } \\ \text { MAGE } & \text { Age (in years) } \\ \text { MAGE2 } & \text { Age }^{2} \\ \text { MGHI } & \text { What is your gross household income? } \\ \text { MRSOUTH } & \text { South of England excluding London } \\ \text { MRMIDWLS } & \text { Midlands and Wales } \\ \text { MRNORTH } & \text { North of England } \\ \text { MRSCOT } & \text { Scotland }\end{array}$

Ten Item Personality Inventory

PXTRAVRT I see myself as extraverted, enthusiastic. I see myself as reserved quiet,

PAGREEBL I see myself as critical quarrelsome, I see myself as sympathetic, warm,

PCONSCS I see myself as dependable, self-disciplined, I see myself as disorganised, careless,

PSTABLE I see myself as anxious, easily upset,

I see myself as calm, emotionally stable,

POPEN I see myself as open to new experience, complex, I see myself as conventional, uncreative 


\section{Titles available in the series:}

Number $1 \quad$ Valuing the environmental impacts of open cast coalmining: the case of the Trent Valley in North Staffordshire Andrew B Trigg and W Richard Dubourg, June 1993

Number $2 \quad$ Scarcity and stability in a very simple general equilibrium model Vivienne Brown, February 1994

Number 3 A conflict model, with rational expectations, of the disinflation of the early 1980s Graham Dawson, February 1994

Number $4 \quad$ Foreign Investment, Globalisation and International Economic Governance Grahame Thompson, May 1994

Number $5 \quad$ Testing the Small Country Hypothesis for Developing Countries Jonathan Perraton, December 1994

Number 6 The Discovery of 'Unpaid Work': the social consequences of the expansion of 'work'

Susan Himmelweit, June 1995

Number $7 \quad$ Exit, Voice and Values in Economic Institutions Graham Dawson, June 1995

Number $8 \quad$ Residential Summer Schools Attendance and Students' Assessed Performances on Open University Foundation Courses Alan Gillie and Alan Woodley, June 1995

Number $9 \quad$ Putting Words into People's Mouths? Economic Culture and its Implications for Local Government Maureen Mackintosh, December 1995

Number 10 What is a Fair Wage? A Critique of the Concept of the Value of Labour-Power Susan Himmelweit, December 1995

Number 11 The Origin of the Poverty Line Alan Gillie, December 1995

Number 12 The Determinants of Product and Process Innovations Roberto Simonetti, Daniele Archibugi, Rinaldo Evangelista, February 1996

Number 13 Technical Change and Firm Growth: 'Creative Destruction' in the Fortune List, 1963-1987 Roberto Simonetti, February 1996

Number $14 \quad$ Utilities vs. Rights to Publicly Provided Goods: Arguments and Evidence from Health-Care Rationing Paul Anand and Allan Wailoo, January 2000

Number 15 Proceeding to the Paddling Pool: The Selection and Shaping of Call Centre Labour George Callaghan and Paul Thompson, January 2000

Number 16 Doing 'Qualitative Research' in Economics: Two Examples and Some Reflections Elizabeth Hill and Gabrielle Meagher, November 1999 
Number 17 Veblen, Bourdieu and Conspicuous Consumption Andrew B Trigg, January 2000

Number 18 The Effect of Idiosyncratic Events on the Feedback between Firm Size and Innovation Mariana Mazzucato, January 2000

Number 19 Non-market relationships in health care Maureen Mackintosh and Lucy Gilson, January 2000

Number 20 Selling pollution and safeguarding lives: international justice, emissions trading and the Kyoto Protocol Graham Dawson, October 2000

Number 21 Entrepreneurship by Alliance Judith Mehta and Barbara Krug, September 2000

Number 22 A disorderly household - voicing the noise Judith Mehta, October 2000

Number $23 \quad$ Sustainable redistribution with health care markets? Rethinking regulatory intervention in the Tanzanian context Maureen Mackintosh and Paula Tibandebage, November 2000

Number 24 Surplus Value and the Keynesian Multiplier Andrew B Trigg, October 2000

Number $25 \quad$ Edwards Revised: Technical Control and Call Centres George Callaghan and Paul Thompson, November 2000

Number 26 Social Norms, Occupational Groups and Income Tax Evasion: A Survey In The UK Construction Industry Maria Sigala, November 2000

Number 27 Procedural Fairness in Economic and Social Choice: Evidence from a Survey of Voters

Paul Anand, December 2000

Number $28 \quad$ Alternative rationalities, or why do economists become parents? Susan Himmelweit, December 2000

Number 29 Agglomeration and Growth: A Study of the Cambridge Hi-Tech Cluster Suma Athreye, December 2000

Number 30 Sources of Increasing Returns and Regional Innovation in the UK Suma Athreye and David Keeble, January 2001

Number 31 The Evolution of the UK software market: scale of demand and the role of competencies

Suma Athreye, September 2000

Number $32 \quad$ Evolution of Markets in the Software Industry Suma Athreye, January 2001

Number $33 \quad$ Specialised Markets and the Behaviour of Firms: Evidence from the UK's Regional Economies

Suma Athreye and David Keeble, January 2001

Number $34 \quad$ Markets and Feminisms

Graham Dawson, January 2001

Number $35 \quad$ Externalities and the UK Regional Divide in Innovative Behaviour Suma Athreye and David Keeble, January 2001 
Number $36 \quad$ Inequality and redistribution: analytical and empirical issues for developmental social policy

Maureen Mackintosh, March 2001

Number $37 \quad$ Modelling the Dynamics of Industry Populations Mariana Mazzucato and P A Geroski, January 2001

Number $38 \quad$ Advertising and the Evolution of Market Structure in the US Car Industry during the Post-War Period (withdrawn) Mariana Mazzucato and P A Geroski, January 2001

Number 39 The Determinants of Stock Price Volatility: An Industry Study Mariana Mazzucato and Willi Semmler, February 2001

Number 40 Surplus Value and the Kalecki Principle in Marx's Reproduction Schema

Andrew B Trigg, March 2001

Number 41 Risk, Variety and Volatility in the Early Auto and PC Industry Mariana Mazzucato, March 2003

Number 42 Making visible the hidden economy: the case for gender impact analysis of economic policy

Susan Himmelweit, August 2001

Number $43 \quad$ Learning and the Sources of Corporate Growth Mariana Mazzucato and P A Geroski, June 2001

Number 44 Social Choice, Health and Fairness Paul Anand, September 2002

Number 45 The Integration of Claims to Health-Care: a Programming Approach Paul Anand, November 2002

Number $46 \quad$ Pasinetti, Keynes and the principle of Effective Demand Andrew B Trigg and Frederic S Lee, June 2003

Number $47 \quad$ Capabilities and Wellbeing: Evidence Based on the Sen-Nussbaum Approach to Welfare Paul Anand, Graham Hunter and Ron Smith, January 2004

Number 48 Entry, Competence-Destroying Innovations, volatility and growth: Lessons from different industries Mariana Mazzucato, June 2004

Number 49 Taking risks with ethical principles: a critical examination of the ethics of 'ethical investment' Graham Dawson, November 2004

Number $50 \quad$ Innovation and Idiosyncratic Risk: an Industry \& Firm Level Analysis Mariana Mazzucato and Massimiliano Tancioni, November 2005

Number $51 \quad$ Industrial Concentration in a Liberalising Economy: a Study of Indian Manufacturing Suma Athreye and Sandeep Kapur, October 2004

Number $52 \quad$ Creating Competition? Globalisation and the emergence of new technology producers Suma Athreye and John Cantwell, October 2005 
Number 53

Number 54

Number 55

Number 56

Number 57

Number 58

Number 59

Number 60

Number 61

Number 62

Number 63

Number 64

Number 65

Number 66
Measuring Human Capabilities (previously entitled "The Development of Capability Indicators and their Relation of Life Satisfaction", released in September 2005)

Paul Anand, Graham Hunter, lan Carter, Keith Dowding, Francesco Guala, Martin van Hees, January 2007

Does International Trade Transfer Technology to Emerging Countries? A Patent Citation Analysis

Elif Bascavusoglu, August 2006

Stock Price Volatility and Patent Citation Dynamics: the case of the pharmaceutical industry (first version published in December 2006) Mariana Mazzucato and Massimiliano Tancioni September 2007

Violent Crime, Gender Inequalities and Well-Being: Models based on a Survey of Individual Capabilities and Crime Rates for England and Wales

Paul Anand and Cristina Santos, January 2007

Innovation and Firm Growth in High-Tech Sectors: A Quantile Regression Approach

Alex Coad (CES-Matisse) and Rekha Rao (LEM) January 2007

Estimating Linear Birth Cohort Effects. Revisiting the Age-

Happiness Profile

Cristina Santos January 2007

Prices of Production are Proportional to Real Costs

Ian Wright January 2007

Temporary Work in Tuscany: a Multinomial Nested Logit Analysis

Lorenzo Corsini (Pisa University) and Marco Guerrazzi (Pisa

University) May 2007

Wage Bargaining in an Optimal Control Framework: A Dynamic

Version of the Right-to-Manage Model

Marco Guerrazzi (Pisa University) June 2007

Innovation and Knowledge Spillovers in Developing Countries

Elif Bascavusoglu July 2007

Firm Growth Dynamics Under Different Knowledge Regimes: the case of the pharmaceutical industry

Pelin Demirel and Mariana Mazzucato September 2007

Planning and Market Regulation: Strengths, Weaknesses and Interactions in the Provision of Less Inequitable and better Quality

Health Care

Maureen Mackintosh October 2007

Investigating the Desperate Housewives: Using gender-role attitudes to explain women's employment decisions in twenty-three European countries

Jerome De Henau October 2007

Struggle over the pie? The gendered distribution of power and subjective financial well-being within UK households

Jerome De Henau and Susan Himmelweit October 2007 